CIVICS EDUCATION AND SOCIAL SCIENSE JOURNAL(CESSJ)

Volume 2 Nomor 2 Edisi Bulan Desember 2020

\title{
PENDAMPINGAN KELUARGA ORANGTUA ANAK USIA DINI YANG MENGALAMI KONDISI UNMET NEED FOR CONTRACEPTION (KESULITAN PEMILIHAN METODE KONTRASEPSI)
}

\author{
Penulis \\ Rina Windiarti ${ }^{1}$, Ali Formen ${ }^{2}$, NenengTasu' ${ }^{3}{ }^{3}$, \\ Desty Citra Sari ${ }^{4}$, MuchamadThoha ${ }^{5}$ \\ PGPAUD, FIP, UNNES, \\ windiarti.rina@mail.unnes.ac.id
}

\begin{abstract}
ABSTRAK
Adanya ledakan penduduk dan kehamilan yang tidak diinginkan yang berujung pada aborsi yang tidak aman akibat dariunmet need contraception (kesulitan dalam memilih metode kontrasepsi) menjadi permasalahan di berbagai negara berkembang, termasuk Indonesia yang merupakan negara dengan penduduk terbesar keempat setelah Cina, India, dan Amerika Serikat. Angka unmet need yang masih tinggi, yaitu 10,5\% (SDKI 2017) berdampak pada tingginya pertumbuhan penduduk, sehingga akan menyebabkan terhambatnya laju pembangunan di berbagai bidang. Oleh karenanya, upaya untuk mengatur kehamilan yang melibatkan lembaga BKKBN perlu ditingkatkan.

Tujuan dilakukannya pengabdian ini adalah untuk memberikan penyuluhan serta pendampingan bagi keluarga yang memiliki anak usia dini yang mengalami kondisi unmet need for contraception, agar dapat mengatur jarak kehamilan antara satu dengan yang lainnya. Metode yang akan dilakukan dalam pengabdian ini adalah dengan memberikan pendampingan bagi orang tua usia subur yang memiliki Anak Usia Dini. Pengabdi terdiri dari tiga orang dosen yang masing-masing memiliki latar belakang bidang keahlian yang berbeda, yaitu: PAUD-pendidikan anak dalam keluarga (1 orang), PAUD-perencanaan pembelajaran (1 orang), PAUD-kebijakan PAUD (1 orang).

Agar pengabdian ini efektif dan tepat sasaran, maka tim pengabdi mengundang satu orang coordinator penyuluh $\mathrm{KB}$ Kecamatan sebagai nara sumber. Isi kegiatan pengabdian ini berupa: (1) penyampaian materi, (2) kegiatan pendampingan, dan (3) review hasil kegiatan pengabdian. Dengan hasil akhir, para peserta pengabdian merasa puas dan tercerahkan karena selama ini selalu bimbang dengan kondisi mereka. Target peserta dalam pengabdian ini sebanyak 21 orang yang terdiri dari tujuh pasang pasangan suami istri. Namun kehadiran peserta sebanyak 19 orang, sehingga dapat dihitung bahwa jumlah peserta yang hadir cukup memenuhi target yaitu sebanyak $90 \%$ yang didapat dari hasil: $(19: 21) \times 100 \%$.
\end{abstract}

Kata Kunci: unmet need, contraception, pasangan subur, orang tua AUD 
CIVICS EDUCATION AND SOCIAL SCIENSE JOURNAL(CESSJ)

Volume 2 Nomor 2 Edisi Bulan Desember 2020

\title{
FAMILY ASSISTANCE FOR PARENTS WITH EARLY YEARS CHILDREN EXPERIENCED WITH UNMET NEED FOR CONTRACEPTION
}

\author{
Author \\ Rina Windiarti ${ }^{1}$, Ali Formen ${ }^{2}$, NenengTasu' $\mathrm{ah}^{3}$, \\ Desty Citra Sari ${ }^{4}$, MuchamadThoha ${ }^{5}$ \\ PGPAUD, FIP, UNNES, \\ windiarti.rina@mail.unnes.ac.id
}

\begin{abstract}
Population explosion and unwanted pregnancies that lead to unsafe abortion due to unmet need contraception have become a problem in developing countries, including Indonesia which is the fourth most populous country after China, India, and United States of America. The high number of unmet need, $10.5 \%$ (2017 IDHS) has an impact on high population growth so that it will hamper the pace of development in various fields. Therefore, efforts to regulate pregnancy involving the $\mathrm{BKKBN}$ institution need to be increased.

The purpose of this service is to provide counselling and assistance for families who have early childhood who experience the conditions of unmet need for contraception which to regulate the distance between pregnancies from one another. The method that will be carried out in this service is to assist parents of childbearing age who have early childhood. The team consists of three lecturers, they are expertise in: education for children in the family (1 person), learning planning (1 person), and ECE policy (1 person).

For this service to be effective and right on target, the team invited one person as a coordinator and expertise in family planning as a speaker. The contents of this activity are in the form of (1) delivery of material, (2) mentoring, and (3) review of the results of service activities. The outcome, most of the participant feel satisfied and enlightened because they have always been uncertain about their condition. The target participants in this service are 21 people consisting of seven pairs of married couples. However, the attendance was 19 people and can be calculated that it met the target of 90\% from the results: (19:21) $\mathrm{x} 100 \%$.
\end{abstract}

Keywords: Unmet need, contraception, fertile spouse, parents with early years 
CIVICS EDUCATION AND SOCIAL SCIENSE JOURNAL(CESSJ)

Volume 2 Nomor 2 Edisi Bulan Desember 2020

\section{PENDAHULUAN}

Indonesia, negara berpenduduk terbanyak keempat setelah Cina, India, dan Amerika Serikat, merupakan negeri yang kaya akan sumber daya alam dan sumber daya manusia. Namun, negara yang dikategorikan sebagai negara berkembang oleh The World Bank ini memiliki berbagai macam permasalahan dibandingkan dengan negara-negara maju, diantaranya adalah masalah kependudukan. Pertambahan jumlah penduduk terus meningkat setiap tahunnya. Hal tersebut menjadi salah satu permasalahan kompleks yang dihadapi oleh negara ini, disamping permasalahan lain seperti: persebaran penduduk tidak merata, tingginya angka beban tanggungan, kualitas penduduk relative rendah, sehingga mengakibatkan tingkat produktivitas penduduk rendah, angka kemiskinan dan pengangguran yang tinggi, serta rendahnya pendapatan perkapita (Atmojo, 2013). Tingginya jumlah penduduk memiliki permasalahan lain yaitu, masalah kehidupan yang layak. Walaupun di sisi lain jumlah penduduk yang melimpah dapat menjadi sumber tenaga kerja.

Permasalahan mengenai jumlah penduduk ini menjadi tantangan bagi negara untuk membuat suatu aturan untuk dapat menekan jumlah kelahiran. Program Keluarga Berencana (KB) yang dicanangkan sejak tahun 1971 mengalami pasang surut dalam pelaksanaannya yang bertujuan untuk membuat keluarga yang harmonis dengan membatasi jumlah anak. Listiyaningsih, dkk (2016) menyatakan bahwa sebelum tahun 2000 kebijakan KB dalam menekan tingkat kelahiran dianggap berhasil. Hal ini terlihat dari adanya penurunan angka fertilitas (kelahiran) di tahun 1991 dari 3,0 menjadi 2,6. Namun, program yang sejatinya ditujukan untuk mengatur jarak kelahiran agar mampu mengoptimalkan pertumbuhan anak ini menjadi gagal (Jalal, 2014; Debora, 2017; Widwiono, 2018) disebabkan karena banyak hal diantaranya, pengetahuan masyarakat yang belum paham tentang alat kontrasepsi, rendahnya jangkauan pelayanan $\mathrm{KB}$, minimnya akses terhadap alat kontrasepsi, kurangnya tenaga kesehatan, serta demografi Indonesia. Dengan gagalnya program $\mathrm{KB}$, maka otomatis akan meningkatnya angka kelahiran, dan ini yang terjadi di Indonesia.

Berdasarkan hasil Survei Penduduk Antar Sensus (SUPAS) tahun 2015, jumlah penduduk Indonesia pada tahun 2020 diprediksikan sebesar 269,6 jutajiwa (Kusnandar, 2020). Proyeksi ini belum dapat terlihat karena sensus di tahun 2020 sedang berlangsung saat ini hingga akhir Maret 2020 (15 Februari hingga 3020), sedangkan sensuster akhir yang dilakukan oleh Badan Pusat Statistik (BPS) dilakukan pada tahun 2010. Jawa Tengah sendiri merupakan salah satu dari tiga provinsi yang mendominasi jumlah populasi di Indonesia, setelah Jawa Barat dan Jawa Timur. Jumlah penduduk di Jawa Tengah tahun 2018 tercatat 34.490.835, naik sebesar 232.970 dari jumlah penduduk di tahun sebelumnya, yaitu 34.257.865 (BPS, 2020). Jumlah kelahiran yang lebih besar dari jumlah kematian di suatu daerah akan menambah jumlah penduduk dari masa ke masa.

Faktor kelahiran, yang menjadi penyebab utama terjadinya kepadatan penduduk dapat diakibatkan dari slogan "banyak anak banyak rejeki" yang telah menjadi kalimat popular sehingga tercipta pola pikir yang mengakar didalam 
lingkungan masyarakat. Hal inimengakibatkan slogan "duaanakcukup" yang digaungkan oleh pemerintah menjadi pudar. Padahal, perencanaan kelahiran anak dapat berdampak positif untuk kesejahteraan dan keberlangsungan hidup di dalam keluarga. Keadaan ini erat kaitannya dengan meningkatkan kesejahteraan ibu dan anak, serta mendukung ibu yang merencanakan pekerjaan untuk mendapatkan penghasilan yang akan meningkatkan taraf ekonomi, sehingga angka kemiskinan dapat berkurang.

Kebutuhan informasi mengenai pentingnya mengetahui alat kontrasepsi bagi pasangan usia subur, dalam hal ini orang tua yang juga memiliki anak usia dini sangat mendesak. Hal ini ditujukkan untuk mengurangi angka unmet need for contraception atau kebutuhan yang tidak terpenuhi untuk alat kontrasepsi. Disebutkan bahwa, angka unmet need di Indonesia masih tinggi dengan angka 12,4\% di tahun 2018 dari target 10,5\% (Wardoyo dalam Prasasti, 2019). Lebih lanjut dijelaskan, sekitar $80 \%$ orang yang melahirkan dan belum ingin memiliki anak dalam satu sampai dua tahun, belum dapat memutuskan jenis kontrasepsi yang dipilih. Dikhawatirkan, pasangan yang baru memiliki anak akan memiliki anak lagi tanpa terencana. Hal ini dapat mengakibatkan terjadinya kehamilan yang tidak dikehendaki, serta meningkatkan angka kematian ibu. Oleh karenanya, diperlukan suatu kegiatan untuk memberikan edukasi pada orangtua yang memiliki anak usia dini dengan informasi mengenai pemilihan alat kontrasepsi yang tepat.

\section{KAJIAN TEORI}

Hasil studi di India mengemukakan bahwa agama, wilayah, dan penolakan suami untuk ber-KB menjadi faktor tingginya unmet need (Kumar, \& Singh, 2013). Sementara itu unmet need di Sudan disebabkan oleh pendidikan rendah para wanita, jenis pekerjaan, dan status pendidikan pasangannya (Ali, \& Okud, 2013). Dengan angka kematian ibu yang tinggi (75\%) di Indonesia dan di dunia yang disebabkan oleh unmet need, BKKBN berusaha untuk menurunkan angka ini dengan program-program KB. Untuk itu, penurunan tingkat unmet need dan mensukseskan program KB bukan hanya menjadi tugas para penyuluh $\mathrm{KB}$ dari BKKBN. Melainkan hal itu memerlukan peran serta dari berbagai lapisan masyarakat terutama dari bidang pendidikan dan kesehatan. Mengedukasi masyarakat membutuhkan waktu dan tenaga yang ekstra, karena harus dapat melayani dengan berbagai macam jawaban dan solusi.

Dewi, dkk (2018) menyebutkan persentase tingkat unmet need di kota Semarang termasuk tinggi yaitu 10,5\% di tahun 2018. Hal inilah yang melandasi bahwa unmet need bukan hanya permasalahan perempuan untuk menunda kehamilannya, tapi juga permasalahan laki-laki, dalam hal ini suami. Suami harus mengetahui seluk beluk tentang kontrasepsi agar pasangan usia subur dapat saling berbagii nformasi. Selain itu, dukungan suami pun sangat diperlukan untuk mendukung kesuksesan dalam ber-KB.

Menurut Haryanto, Santoso, dan Palmore (1992) dalam Tiya (2013), unmet need for contraception terbagi menjadi dua yaitu, (1) Manifest Unmet need 
for contraception, dan (2) Latent Unmet need for contraception. Dua jenis persoalan ini dapat dijelaskan sebagai berikut.

a. Manifest Unmet need for contraception, dikategorikan sebagai

1) Wanita kawin usia subur, tidak hamil, menyatakan tidak ingin punya anak lagi dan tidak memakai kontrasepsi modern seperti IUD, pil, suntik, implant, obat vaginal dan kontrasepsi mantap untuk suami atau dirinya sendiri.

2) Mereka yang ingin menunda kehamilan berikutnya tetapi tidak memakai alat kontrasepsi seperti yang telah tersebut.

3) Mereka yang sedang hamil tetapi kehamilan tersebut tidak dikehendaki lagi pada saat itu dan pada waktu sebelum hamil tidak memakai alat kontrasepsi.

4) Mereka yang sedang hamil tetapi saat terjadinya kehamilan itu belum sesuai dengan waktu yang dikehendaki dan sebelumnya tidak memakai alat kontrasepsi

b. Latent Unmet Need, yaitu mereka yang tidak memakai alat kontrasepsi di luar kelompok manifest Unmet Need KB tersebut, yaitu:

1) Mereka yang ingin masih tambah anak lagi, tetapi jumlah anak yang diinginkan lebih dari dua orang.

2) Mereka yang menunda untuk anak berikutnya (anak kedua), tetapi lama waktu penundaan kurang dari tiga tahun.

3) Mereka yang sedang hamil atau menopause setelah kelahiran anak kedua, tetapi jarak antara kehamilan kedua dengan kelahiran anak pertama kurang dari dua tahun.

Pembagian unmet need yang lain adalah, (1) unmet need for spacing, yaitu untuk menjarangkan, dan (2) unmet need for limiting (untuk membatasi atau mengakhiri kesuburan)

Berdasarkan dari hasil penelitian terdahulu mengenai tingginya unmet need for contraception, serta pentingnya pemberian informasi mengenai topik ini, tim pengabdi merencanakan untuk membuat pendampingan bagi masyarakat melalui layanan penyuluhan dan penyampaian informasi mengenai topik unmet need for contraception. Hal ini dilakukan agar masyarakat di era disruptive ini dapat mengetahui dan memperoleh informasi tentang berbagai alat kontrasepsi, bagaimana penggunaannya, serta di mana cara mendapatkannya. Tidak hanya itu, dalam pengabdian ini akan dijelaskan pula materi tentang pengasuhan dan kesehatan anak. Materi ini berkolerasi dengan materi unmet need, sebab sasaran dari pengabdian ini adalah pasangan orang tua yang memiliki anak usia dini.

Alasan dipilihnya wilayah Ngijo sebagai tempat pengabdian adalah karena di wilayah ini memiliki jumlah penduduk relative padat. Berdasarkan data yang kami himpun, jumlah total penduduk berjenis kelamin laki-laki berjumlah 2.253 jiwa. Sedangkan jumlah total penduduk perempuan berjumlah 2.232 jiwa. Total RT yang ada di Kelurahan ini adalah 22. Jumlah penduduk yang padat merupakan campuran antara penduduk asli wilayah tersebut, dan juga pendatang dari berbagai daerah dan menetap disana. Dengan latar belakang tingkat Pendidikan yang 
berbeda menjadi adanya gap. Ditambah dengan minimnya pemahaman penduduk mengenai pemilihan alat kontrasepsi yang tepat, menjadi hal yang perlu diinformasikan kepada masyarakat. Hal ini terbukti dengan adanya keluarga yang memiliki anak dengan jarak yang berdekatan, sehingga orang tua sendiri merasa kerepotan dalam mengasuh dan mendidik anak-anaknya. Dengan adanya sosialisasi mengenai penggunaan alat kontrasepsi yang tepat difungsikan agar penduduk di daerah Ngijo dapat merencanakan kehamilan sesuai dengan yang dianjurkan oleh pemerintah. Permasalahan ini sepertinya sangat sederhana, namun jika masyarakat tidak memahaminya, maka akan merugikan mereka sendiri, yang berujung pada lonjakan penduduk yang tidak terkontrol. Penyuluhan ini ditujukan untuk mensejahterakan kehidupan masyarakat yang sehat dan cerdas di wilayah ini.

Anggota dalam pengabdian ini terdiri dari dosen PAUD yang memiliki latar belakang keilmuan yang berbeda (kebijakan PAUD, perencanaan PAUD, dan ke-PAUD-an). Pengabdian ini juga mengikutsertakan dokter yang juga merangkap sebagai dosen, serta turut serta penyuluh $\mathrm{KB}$ yang bertugas di BKKBN Jawat Tengah dan memiliki pengalaman serta pengetahuan luas mengenai bahasan utama dalam pengabdian ini. Pengabdi yakin, dengan anggota pengabdian yang memiliki latar belakang Pendidikan yang berbeda dan professional dibidangnya dapat membuat pengabdian ini menjadi kaya ilmu. Dan diharapkan ilmu yang diberikan dapat diaplikasikan dalam keseharian peserta pengabdian.

\section{METODE}

Metode yang dilaksanakan adalah dengan menggunakan teknik pendidikan andragogy atau pembelajaran untuk orang dewasa. Teknik ini dipilih dan digunakan mengingat topik bahasan dalam pendampingan ini kemungkinan akan menjadi topik yang sensitive karena berhubungan dengan permasalahan pribadi antar pasangan usia subur. Untuk mengatasi permasalahan lain mengenai sulitnya mengajak para suami ikut serta dalam kegiatan ini, maka pengabdi memiliki solusi untuk memberikan reward kepada para suami yang mau berpartisipasi mendampingi istrinya untuk hadir dalam pendampingan. Agar pendampingan ini dapat efektif dan tepat sasaran, maka pemberian reward untuk peserta menjadi salah satu cara untuk menarik peserta datang dalam pendampingan pengabdian ini.

Metode dalam pelaksanaan pendampingan dalam kegiatan pengabdian ini menggunakan teknik interaksi social bagi orang tua yang memiliki anak usia dini atau Pasangan Usia Subur (PUS). Dengan mendayagunakan Penyuluh KB yang tergabung di dalam pengabdian ini, diharapkan tujuan $\mathrm{KB}$, manfaat $\mathrm{KB}$, pemilihan alat dan jenis kontrasepsi, serta bahaya apa jika ber-KB ditinjau dari segi social dan medis dapat tersampaikan dengan jelas dan dipahami oleh partisipan. Sehingga jarak kehamilan dapat diatur. 
Pengabdian ini menghadirkan koordinator penyuluh $\mathrm{KB}$ untuk memberikan edukasi kepada pasangan subur mengenai materi di sesi pertama. Alasan mengikut sertakan penyuluh adalah karenas esuai dengan bidangnya dan telah memiliki berbagai pengalaman dalam menangani permasalahan mengenai kasus-kasus dalam meningkatkan keluarga berencana.

\section{HASIL PENELITIAN DAN PEMBAHASAN}

\section{PenyampaianMateritentangUnmet Need for Contraception}

Informasi dan edukasi mengenai pemilihan metode kontrasepsi telah dilaksanakan pada tanggal 25 Juli 2020 dengan total peserta sebanyak 19 orang yang terdiri dari pasangan suami-istri. Alasan tim pengabdi membatasi peserta dari pasangan suami-istri karena untuk membahas mengenai hal ini bukan hanya permasalahan perempuan atau istri saja, tapi juga membutuhkan pemahaman dari para suami agar dapat selalu mendukung istri dalam merencanakan kehamilan dan kelahiran. Sehingga harapannya, sebuah keluarga dapat betul-betul terencana agar kesejahteraan keluarga dan anak terutama, dapat meningkat.

Paparan pertama dilakukan oleh narasumber pertama, Endah Sri Wahyuningsih, S.Sos, M. I.Kom; membahas lebih detail dan teknis mengenai kontrasepsi dan permasalahannya. Dalam memberikan informasi mengenai hal ini, narasumber menggunakan pendekatan pembelajaran untuk orang dewasa, dimana tanya jawab sering dilontarkan untuk memperdalam informasi dari peserta pengabdian. Materi yang disampaikan mencakup informasi tentang:

1) Keluarga Berencana

2) Peran $\mathrm{KB}$ dalam peningkatan kualitas penduduk

3) Mengenal jenis-jenis kontrasepsi

4) Jenis-jenis metode kontrasepsi, serta

5) Mitos dan fakta mengenai kontrasepsi

\section{PenyampaianMateritentang Peran Suami/laki-laki}

Setelah paparan pertama selesai, dilanjutkan dengan paparan kedua oleh salah satu anggota tim pengabdian, Ali Formen, Ph.D yang membahas mengenai kebutuhan keluarga dan peran suami dalam mendukung peran istri sebagai ibu dan juga orang yang memiliki andil dalam mengurus keluarga. Data serta grafik peran laki-laki dalam mendukung kontrasepsi baik di Indonesia dan diluar negeri ditampilkan dalam paparan ini.

Sesi terakhir merupakan sesi tanya jawab dari peserta pengabdian kepada kedua narasumber. Dalam sesi ini, antusias peserta untuk bertanya ternyata di luar dugaan, karena banyaknya pertanyaan. Namun, karena waktu yang terbatas, tidak semua pertanyaan dapat dijawab oleh narasumber. Karena pertanyaan-pertanyaan yang dilontarkan tersebut dijawab dengan detail oleh para narasumber. Kegiatan pengabdian ini dilaksanakan secara 
daring dengan memanfaatkan aplikasi zoom dan dihadiri oleh tujuh pasang suami istri yang sebelumnya telah mendaftar melalui google form. Pelaksanaan pengabdian di hariSabtu, tanggal 25 Juli 2020.

\section{KegiatanPendampingan}

Kegiatan pendampingan dilakukan setelah pelatihan selesai dilaksanakan. Peserta dapat bertanya tentang kesulitan-kesulitan yang dialami saat perasaan galau dan belum mendapatkan solusi mengenai apa yang dirasa terbaik untuk program KB yang akan diambil. Kegiatan pendampingan juga dilakukan secara offline dengan melibatkan peserta pengabdian untuk dapat menghubungi langsung melalui personal chat ke nomor WhatsApp pemateri yang merupakan penyuluh KB di wilayah Kecamatan Gunungpati.

\section{Review Hasil KegiatanPengabdian}

Berdasarkan hasil pertemuan pendampingan, para peserta berupa pasangan suami istri menyatakan puas dan senang dengan adanya kegiatan pengabdian ini. Puas karena pertanyaan-pertanyaan mereka selama ini yang belum terjawab, dapat mereka dapatkan dengan adanya pendampingan. Selain itu, informasi lain mengenai adanya mitos dan fakta yang telah dipaparkan menjadi salah satu ilmu baru yang menjadi bekal mereka dalam mengimplementasikan program KB. Diharapkan pada tahun-tahun selanjutnya dapat dilaksanakan kembali kegiatan ini dengan jumlah peserta yang lebih banyak agar informasi dapat tersebar dengan maksimal.

Dari hasil diskusi dan pendampingan setelah kegiatan pengabdian, 8 dari 19 peserta pengabdian menyatakan bahwa mereka bingung untuk memilih alat kontrasepsi apa yang tepat untuk digunakan; karena ingin memberi jarak untuk kehamilan berikutnya. Dari beberapa hasil penelitian, kebingungan dalam pemilihan alat kontrasepsi menjadi hal yang dapat mengakibatkan tingginya angka kegagalan dalam penundaan untuk memiliki anak. Akan menjadi permasalahan yang berarti jika sebuah keluarga yang masih memiliki anak usia dini, kemudian bertambah anggota keluarga dengan hadirnya bayi yang baru lahir. Ibu, sebagai kunci dalam keseimbangan sebuah keluarga memiliki peran yang sangat besar. Jika kondisi ibu dalam mengurus dan mendidik satu anak belum tuntas, kemudian ketambahan lagi dengan beberapa anak yang membutuhkan perhatian; maka dapat diperkirakan bahwa kesejahteraan ibu dan juga anak menjadi tidak terwujud.

Bukan saja kesejahteraan ibu, anak serta keluarga yang menjadi permasalahan; akan tetapi tingginya Angka Kematian Ibu (AKI) selama hamil atau setelah berakhirnya kehamilan menjadi faktor utama yang perlu dicermati. Kemenkes RI (2018) mencatat, kematian ibu dirumuskan sebagai 4 Terlalu 3 Terlambat yaitu,

1. Terlalu muda $(<20$ tahun),

2. Terlalu tua ( $>35$ tahun),

3. Terlalu sering atau banyak anak ( $>3$ anak),

4. Terlalu dekat jarak kelahiran $(<2$ tahun) 
CIVICS EDUCATION AND SOCIAL SCIENSE JOURNAL(CESSJ)

Volume 2 Nomor 2 Edisi Bulan Desember 2020

5. Terlambat mengambil keputusan

6. Terlambat sampai di fasilitas Kesehatan

7. Terlambat mendapatkan pertolongan yang adekuat

Berdasarkan poin-poin tersebut, beberapa poin sesuai dengan kondisi 4 peserta pengabdan, yaitu anak lebih dari 3, jarak kelahiran yang berdekatan, dan juga usia kehamilan diatas usia 35 tahun. Saat mengetahui hal inilah, kemudian narasumber memberikan informasi dan solusi untuk dapat mensiasati kerawanan tersebut dengan mengatur interval diantara kehamilan, mengontrol waktu saat kelahiran, serta menentukan jumlah anak dalam keluarga (Suratun dalam Astuti \& Ilyas, 2015). Oleh karena itu, program KB memiliki andil untuk dapat mengendalikan laju pertumbuhan penduduk, dan juga pembinaan ketahanan dan peningkatan kesejahteraan keluarga dalam mewujudkan keluarga yang Bahagia dan sejahtera.

Dari paparan yang diberikan oleh narasumber, beberapa pertanyaan dari para suami juga muncul mengenai kecilnya jumlah akseptor laki-laki karena pada dasarnya untuk membeli alat kontrasepsi berupa kondom dapat ditemui dimanapun. Menurut Raidanti (2018), sesungguhnya bukan permasalahan akses alat kontrasepsi yang mudah ditemui; akan tetapi usia, pendidikan, dan dukungan tokoh agama mempengaruhi akseptor $\mathrm{KB}$ pada pria. Lebih lanjut dijelaskan bahwa penghasilan, jumlah anak, dan dukungan isteri bukan termasuk factor yang dapat mempengaruhi kecilnya jumlah akseptor KB pada pria. Akan tetapi, pentingnya mendorong ibu rumah tangga untuk mengajak pasangan/suami ikut ambil bagian dalam pengambilan keputusan mengenai penggunaan metode kontrasepsi sangat diperlukan agar dapat terlibat secara langsung dalam penggunaan pelayanan keluarga berencana terutama penggunaan kondom bagi suami (Yeni, dkk. 2017).

Dalam penelitian lain disebutkan beberapa alasan para ibu tidak menggunakan kontrasepsi sebagai berikut (Sedgh, dkk. 2016):

1. Kurangnya informasi mengenai kontrasepsi

2. Jarang berhubungan dengan suami

3. Menstruasi tidak teratur

4. Alasan kepercayaan

5. Ketidaknyamanan dengan alat kontrasepsi

Hal-hal ini akan menjadi permasalahan luas jika tidak segera tertangani. Diperlukan adanya kerja sama dari berbagai pihak untuk dapat memberikan solusi atas permasalahan tersebut.

Untuk menekan tingginya jumlah unmet need for contraception perlu mencermati apa saja factor-faktor yang mempengaruhi kesulitan dalam memilih alat kontrasepsi yang tepat. Jursiman, Ariadi, \& Kurniati (2016) menyebutkan bahwa, tingkat pendidikan memiliki hubungan yang bermakna dengan pemilihan alat kontrasepsi. Lebih lanjut dijelaskan bahwa, tingkat Pendidikan ibu yang tinggi cenderung memilih kontrasepsi IUD. Selain Pendidikan, usia, paritas, dan 
pengalaman KB juga berhubungan dalam pemilihan metode kontrasepsi (Indahwati, Wati, Wulandari. 2017).

Pertanyaan lanjutan dari peserta mengenai kontrasepsi dengan hukum Islam dijabarkan oleh narasumber sebagai berikut: Jika ditelusuri lebih lanjut, tindakan untuk menghindari kehamilan telah diajarkan di masa Rasulullah, yang disebut dengan ' $a z l$, yaitu dikeluarkannya sperma di luar rahim. Hal ini sesuai dengan penelitian yang dilakukan oleh Handayany (2013) yang menyebutkan bahwa, tindakan dengan menggunakan system kalender kondom, dan lain sebagainya diperbolehkan untuk menghindari terjadinya pembuahan. Sehingga jarak kehamilan dan kelahiran dapat diatur karena akan berdampak pada ibu, anak, dan keluarga; karena kesehatan dan kesejahteraan keluarga harus tetap terjaga. Dalam Al-Qur'an juga dijelaskan mengenai masa menyusui bagi bayi yaitu hingga dua tahun. Artinya, hal ini menjadi acuan bahwa terdapat jarak bagi ibu untuk dapat hamil kembali setelah tiga tahun (Handayany, 2013). Karena setiap bayi yang dilahirkan memiliki hak untuk menyusui selama dua tahun, dan ibu memiliki hak untuk dapat beristirahat.

\section{SIMPULAN}

Kegiatan pengabdian dilakukan pada hari Sabtu tanggal 25 Juli 2020 dengan lancar dan sesuai harapan. Target peserta dalam pengabdian ini sebanyak 21 orang yang terdiri dari tujuh pasang pasangan suami istri. Namun kehadiran peserta sebanyak 19 orang, sehingga dapat dihitung bahwa jumlah peserta yang hadir cukup memenuhi target yaitu sebanyak 90\% yang didapat dari hasil: (19:21) $\mathrm{x} 100 \%$. Banyaknya pertanyaan dari peserta menandakan respon positif dalam kegiatan edukasi ini. Namun tidak semua pertanyaan dapat dijawab oleh narasumber, sehingga solusi yang diberikan adalah pendampingan secara personal melalui chat WA. Di akhir kegiatan, para peserta mengungkapkan kepuasan atas jawaban dari para narasumber, dan merasa bahwa mereka tercerahkan serta menjadi mantap untuk menggunakan alat kontrasepsi yang sesuai dengan pilihannya. 
CIVICS EDUCATION AND SOCIAL SCIENSE JOURNAL(CESSJ)

Volume 2 Nomor 2 Edisi Bulan Desember 2020

\section{REFERENSI}

Ali, A. A. A., \& Okud, A. 2013. Factors affecting unmet need for family planning in Eastern Sudan. Springer. Online [diakses: 27/2/2020] https://link.springer.com/article/10.1186/1471-2458-13-102

Ardhika, M. U. R. 2018. Faktor Penyebab Terjadinya Unmet Need KB Pasangan Usia Subur (PUS) di Kecamatan Labuhan Ratu Kota Bandar Lampung. Skripsi. FKIP, Universitas Lampung.

Astuti, D., Ilyas, H. 2015. Faktor-faktor yang berhubungan dengan pemilihan alat kontrasepsi suntik. Jurnal Keperawatan. Vol. XI, No. 2. ISSN 19070357.

Atmojo, S. D. 2013. Masalah Kependudukan di Indonesia sebagai Negara Berkembang. Kompasiana. Online [diakses: 27/2/2020]

https://www.kompasiana.com/satriodwiatmo/5520acfba33311a24646d11c/masalah-kependudukan-diindonesia-sebagai-negara-berkembang

Debora, Y. 2017. Nasib Program Keluarga Berencana di Ujung Tanduk. Artikel. Online [diakses: 27/2/2020] https://tirto.id/nasib-program-keluargaberencana-di-ujung-tanduk-csoP

Dewi, F. R., Winarni, S., \& Nugroho. D. 2018. Hubungan Beberapa Faktor dengan Kejadian Unmet Need Keluarga Berencana di Kelurahan Bulu Lor. Jurnal Kesehatan Masyarakat, Vol. 6 No. 4. Online [diakses $27 / 2 / 2020]$

Handayany, G. N. 2013. Kontrasepsi dalam kajian Islam. Jurnal Al-Fikr. Vol. 17, No. 1, h. 231-244.

Indahwati, L., Wati, L. W., Wulandari, D. T. 2017. Usia dan pengalaman KB berhubungan dengan metode kontrasepsi. Journal of issues in Midwifery. Vol. 1, No. 2; 9-18. E-ISSN : 2549-6581

Jalal, F. 2014. Program KB Gagal, Angka Kelahiran Meningkat. Artikel, Berita Satu. Online [diakses: 27/2/2020] https://www.beritasatu.com/kesehatan/227612/program-kb-gagal-angkakelahiran-meningkat

Jurisman, A., Ariadi, Kurniati, R. 2016. Hubungan karakteristik ibu dengan pemilihan kontrasepsi di puskesmas Padang Pasir Padang. Jurnal Kesehatan Andalasi. 5 (1). 
CIVICS EDUCATION AND SOCIAL SCIENSE JOURNAL(CESSJ)

Volume 2 Nomor 2 Edisi Bulan Desember 2020

Kemenkes RI. 2018. Warta Kesmas: Menjaga Kesehatan Ibu dan Anak (Ed. 3). Kesmas.kemkes.go.id.

Kumar, A., \& Singh, A. 2013. Trends and determinants of unmet need for family planning in Bihar (India): evidence from National Family Health Surveys. Journal of Advances in Applied Sociology, Vol. 3 No. 2, h. 157-163. Online [diakses: 27/2/2020] https://researchportal.port.ac.uk/portal/en/publications/trends-anddeterminants-of-unmet-need-for-family-planning-in-bihar-indiaevidence-from-national-family-health-surveys(b44de621-0037-48de$\underline{\text { 81e0-13bbb94c5371).html }}$

Kusnandar, V. B. 2020. Inilah Proyeksi Jumlah Penduduk Indonesia 2020. Online [diakses: 27/2/2020] https://databoks.katadata.co.id/datapublish/2020/01/02/inilah-proyeksijumlah-penduduk-indonesia-2020

Listiyaningsih, U., Sumini, \& Satiti, S. 2016. Unmet Need: Konsep yang masih perlu Diperdebatkan. Jurnal Populasi, Vol 24 No. 1, hal. 72-90.

Prasasti, G.D. 2019. Kepala BKKBN: Banyak Pasangan Tak Ingin Punya Anak Lagi tapi Belum pakai Kontrasepsi. Artikel, Liputan 6. Online [diakses: 27/2/2020] https://www.liputan6.com/health/read/4058427/kepala-bkkbn-banyakpasangan-tak-ingin-punya-anak-lagi-tapi-belum-pakai-kontrasepsi

Raidanti, D. 2018. Analisis Faktor-faktor yang mempengaruhi akseptor KB pria di Kecamatan Salembaran Jaya Kabupaten Tangerang Propinsi Banten. Jurnal JKFT. Vol. 3, No. 1. DOI (PDF): http://dx.doi.org/10.31000/jkft.v3i1.1016.g643.

Sedgh, G., Ashford, L. S., Hussain, R. 2016. Unmet need for contraception in developing countries: examining women's reasons for not using a method. Report. Guttmacher Institute. New York.

Tiya, K. 2013. Dampak Intervensi Model Penurunan Unmet Need KB dan Peningkatan KB Pria Terhadap Pencapaian Sasaran Program Dhs-I Pada Program KB di Provinsi Sulawesi Tenggara1. Jurnal gema Pendidikan, vol. 20 No. 2. Online [diakses: 28/2/2020]

http://ojs.uho.ac.id/index.php/GP/article/view/2790

Ulsafitri, Y., \& Fastin, R. N. 2016. Faktor-faktor yang berhubungan dengan Unmet Need KB pada Pasangan Usia Subur (PUS). Jurnal Kesehatan. Prodi D III Kebidanan. STIKes YARSI, Sumatera Barat. [Diakses: 27/2/2020] 
CIVICS EDUCATION AND SOCIAL SCIENSE JOURNAL(CESSJ)

Volume 2 Nomor 2 Edisi Bulan Desember 2020

Widiwiono. 2018. Ini Penyebab Program Keluarga Berancana Gagal. Artikel, Warta Kota. Online [diakses: 27/2/2020] https://wartakota.tribunnews.com/2018/02/20/ini-penyebab-programkeluarga-berencana-gagal

Yeni, dkk. 2017. Paritas dan peran serta suami dalam pengambilan keputusan terhadap penggunaan metode kontrasepsi. Jurnal MKMI. Vol. 13, No. 4. 